\title{
Developing System Thinking Approach for Sustainable Destination Management in Lake Toba
}

\author{
Ricardo Situmeang \\ Engineering Management, Faculty of Industrial Technology. Del Institute of Technology Jalan Sisingamangaraja Sitoluama Laguboti \\ Toba Samosir North Sumatera Indonesia
}

\begin{abstract}
Lake Toba as one of the largest natural lake in the world occupying the caldera of super-volcano features diverse topography, remarkable historical heritage and archeological value. Because of its unique and rich features, lake toba has become a popular destination for tourists. Considering the significance and the potential of the tourism industry for economic development of the society both locally and nationally, there is an urgency to establish competitiveness and attractiveness the destinations using effective and sustainable strategies based on the market conditions, and the other to balance of interests of stakeholders. The aim of this study is to propose the important of developing system thinking for destination management to be sustainable, as well as the opportunities to pursue strategic policies and conditions for constituting different types of management structures. The process includes the development of a systems thinking approach that represents a holistic understanding of the interconnectedness and relationships between the various components that impact on sustainable development of tourism in Lake Toba. The paper is intended to use this as a framework for decisions and capacity building by government and private stakeholders who share the responsibility in developing, managing and sustaining the system.
\end{abstract}

\section{Introduction}

Destination development is a dynamic and complex system which contains numerous components that involves a diverse array of stakeholders. These components are interconnected through non-linear relationships while each stakeholder holds different objective, agendas and interests. It requires management of all tourist resources. This is a holistic process that ensures tourism adds value to our economy, social fabric and ecology of our communities. Tourism can be an economic driver, generating jobs and contributing vibrant lifestyle benefits to our communities. At the same time it should maintain cultural integrity, essential ecological processes, biological diversity and life supporting ecosystems.

This often causes conflict that necessitates compromises based on a better understanding of each other's needs and requirements. The tourism system is also strongly influenced by various internal and external factors resulting in an extremely complex and dynamic system with high levels of uncertainty and unpredictability. In order to manage the system in a sustainable way, it is necessary to provide stakeholders with effective learning mechanisms to align their views, to help them make more informed decisions, and to adapt to the continually changing environments.
At the same time tourism needs to be managed to ensure that it leaves a positive legacy for current and future generations. Importantly the tourism sector needs to ensure that it is considered in the broader context of regional development and that it is recognized for its overall contribution and economic value to the region. To be effective, planning, development and marketing activity must be based on research and the needs of the consumer. To compete effectively, destinations have to deliver wonderful experiences and excellent value to visitors. (Sterman, 2002)

Destination Management Organization (DMO) in Indonesia has been implemented since 2011 by the Ministry of Tourism in 16 destination clusters. One of the characteristics of DMO is the utilization of network approach consisted of key agents of tourism in developing communication on tourism development in the area. Ownership on sustainable management in destination area has become one of the important aspects in competitiveness improvement. Such improvement is hoped to minimize the local and sectorial ego appeared from the implementation of regional autonomy. The power of governance development collaboration creates the helpful communication, partnership, and coordination in destination area i.e. also region. DMO is considerably new in Indonesia. If management is divided into three dimensions; structural (public), nonstructural (sociocultural, community) and market (business), then DMO is a part of the nonstructural dimension. The role of 
DMO is to reinforce and empower the existing management pattern, thus it complement the structural governance in public and private sector. (Ministry of Tourism, 2016)

Lake Toba development focused on the preservation of natural and cultural creativity of communities around Lake Toba. Lake Toba is now being promoted as geopark tourist area. There are priority tourist destinations that are become government focus such as to provide added value to the sustainability, development of tourist destinations, developing infrastructures and accessibility. (Lumbanraja, 2012).

DMO program in Lake Toba is one of priority for Indonesian government that is to design strategy and action plan for tourism development in Lake Toba. Developing destinations in Lake Toba require spatial integration, support facilities and infrastructure, connectivity and accessibility as well as amenities with various support facilities. To create multi sector development required an integrated process that aims to build commitment of stakeholders in developing DMO program in Lake Toba. (Ministry of Tourism, 2015)

Before developing tourism plan in Lake Toba, it is important to consider market potential that appeal to conditions, infrastructure, accessibility, and management, regulatory, economic and social value. (Teguh, 2015)

\section{Tourism system models}

The competitiveness and attractiveness of the destinations suggest the use of effective, sustainable strategies and systems that are based on market conditions and preferences, as well as on the balancing of interests inside the tourist destination. Currently, the call for systemic change is becoming increasingly strident. Unfortunately, the word system has been popularized without a fundamental understanding of its implications, to the point where everything is a system but nothing really is treated as one. Many people say they are using a systems approach, but almost no one really is. Furthermore, popular interpretations of systems tend to use inappropriate mechanical models and metaphors. Decision makers need to fully understand why our current approaches won't work and what is different about the systems approach. (Senge, 2010)

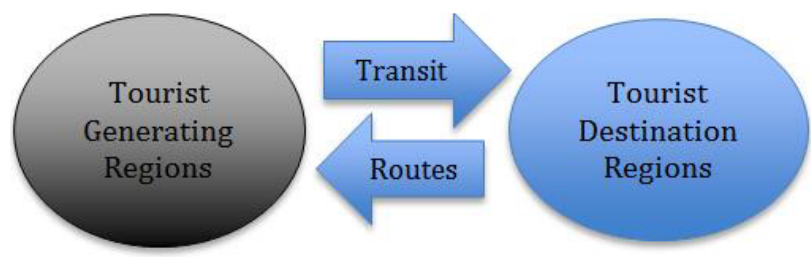

Environments : Human, socio cultural, economical, technological, physical, political, legal etc

Figure 1. The geographical components of tourism. Source :Leiper (1979)

\subsection{Tourism system}

For the last decade, we are introduced with various models of tourism development. Most of them are focused on destination areas instead of defining them as "system" (Gunn, 1994; Leiper, 1990; Mill \& Morisson, 1998). Generally, a system has a structure and the environments (Bertalanffy, 1971).

\subsection{The destination life cycle model}

Destination development is about creating and maintaining visitor experiences, saleable products and services that meet visitors' needs and expectations and facilitate their travel and stay within a destination. Traditionally this focus has been on assets and products. Increasingly visitors are looking to enjoy unique and fulfilling experiences that bring a destination to life and make it memorable. The most authentic visitor experiences may be developed outside the regular tourism offering. These will provide opportunities for visitors to experience the landscape, people, way of life, culture and food enjoyed by the local community. Make sure to invest in soft infrastructure rather than just hard infrastructure such as transport, accommodation and transport.

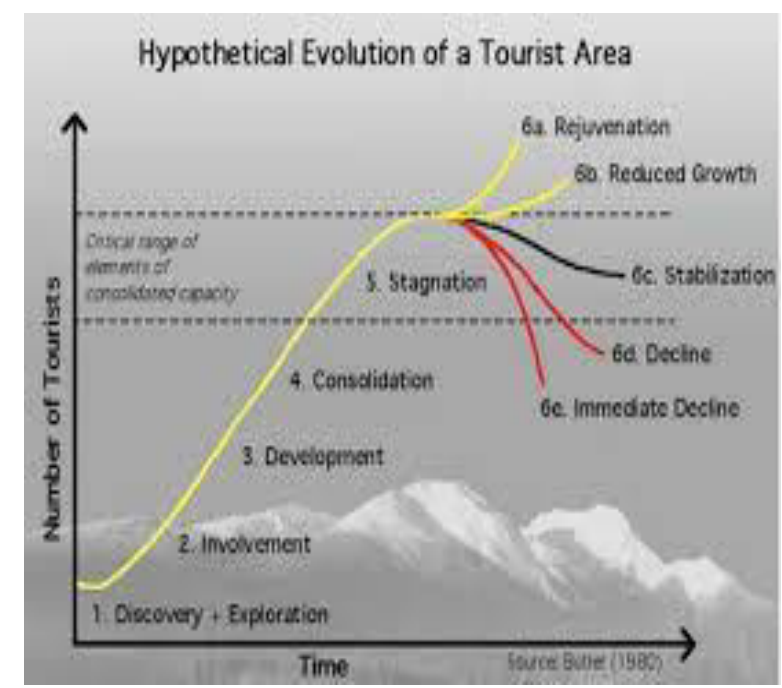

Figure 2. Destination life cycle approach (Buttler, 1980)

Buttlers model (1980), has become of the best known theories of tourism evolution at destinations (Weaver \& Lawton, 2002). This model represents the relationship between an increasing number of tourists and the development of a tourist over time, as a life cycle. The cycle includes six stages: exploration, involvement development, consolidation, stagnation and poststagnation. This model also explains the involvement process of the local community in those stages

\section{System thinking approach}

System thinking allows people to make their understanding of social systems explicit and improve them in the same way that people can use engineering principles to make something explicit. Systems thinking will help us to understand the value of other opinions, and ability to see things from different perspective. A mental models which is ingrained assumptions that ultimately influence how we see things and what we do, can be a good place to start. (Meadows, 2008) 
The habits of systems thinkers include: considering long and short-term consequences of actions such as, identifying the circular nature of complex cause and effect relationships (the bee buzzing around the flower is a system, where the bee needs the flower and the flower needs the bee); and looking at things from different angles and perspectives.

Systems thinking approach is fundamentally different from traditional form of analysis. Traditional analysis focused on the separating the individuals pieces of what is being studied. Systems thinking is not just about the tools to help us see the world with a better lens; it also can give us greater grasp of why things happen a certain way. Traditional thinking often see things in linear ways without considering others perspectives and its relationships. Things are circular in systems thinking, and recognizing the complex nature of cause-and-effect relationships can help us to understand why things happen.(Senge, 2010

\section{Linear Thinking}

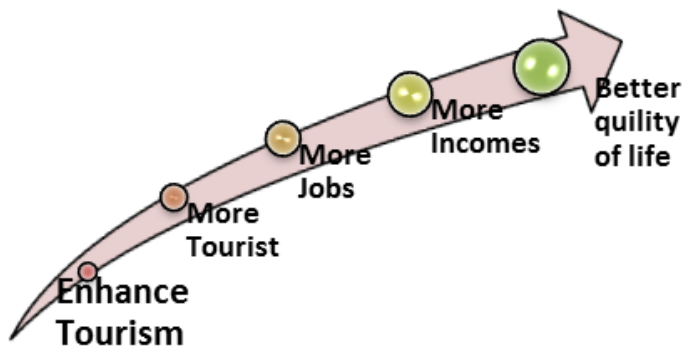

Figure 3. Linear thinking approach source: Modification ricardo, 2016

\section{System thinking for sustainable tourism development in Lake Toba}

\subsection{Backgrounds}

The application of systems thinking has grown extensively and encompassed work in many diverse fields such as business (Sterman, 2000), health (Cavana, Davies, Robson, \& Wilson, 1999), commodity systems (Sawin, et al., 2003), agricultural production systems (J. Wilson, 2004), natural resource management (Allison \& Hobbs, 2006), environmental conflict management (Elias, 2008), decision making and consensus building (Kambiz E Maani, 2002; Kambiz E Maani \& Maharaj, 2004), and human resource management (Quatro, Waldman, \& Galvin, 2007) Nevertheless, this is the first study using a systems thinking approach to apply in the sustainable development of tourism in a biosphere reserve context. It would therefore have high potential to be applied globally, considering the importance of tourism in many economies and a comprehensive network of Lake Toba (UNESCO, 2009)

Using systems thinking approaches for developing integrated destination management organization will enable us to see from another perspective and look deeper to why some events play out in certain ways. If we develop those habits of thinking systemically and look at any tourisms issue, we will ask different questions. This means that instead of isolating smaller parts of system being studied, we can develop something strikingly different conclusions than those generated by traditional forms of analysis, especially when what is being studied is dynamically complex or has a great deal of feedback from other sources, internal and external. This approach has been developed as an emerging discipline to understand complexity and dynamic changes (K. Maani, E. \& Cavana, 2007). In addition, it offers new powerful paradigm, a specialized language and methodology.

The character of system thinking makes it extremely effective on the most difficult types of problems to solve: those involving complex issues, those that depend a great deal dependence on the past or on the actions of others, and those stemming from ineffective coordination among those who involved. Many important problems that plague us today are complexes, involve multiple actors, and are at least partly the result of past actions that were taken to alleviate them. Dealing with such problems is notoriously difficult and the results of conventional solutions are often poor enough to create discouragement about the prospects of ever effectively addressing them. One of the key benefits of systems thinking is its ability to deal effectively with just these types problems and to riase our thinking to the level at which we create the results we want as individuals and organizations even in those difficult situations marked by complexity, great numbers of interactions and the absence or ineffectiveness (Sterman, 2002)

\subsection{System Thinking Approach : Process and Results}

Maani and Cavana (2007) simplified the approach by using the analogy of an iceberg to visualize four levels of thinking (Fig. 6). The events level represents the tip of the iceberg which describes symptoms of reality. However, most of the decisions and interventions take place at this level. This is because events are the most visible part and often require immediate attention and action (Maani and Cavana 2007).Therefore, it often receives quick fixes and leads to "fire fighting" or "band aid" behavior (Bosch, et al., 2007). The next level of thinking is patterns where a larger set of data points are linked together to create the trends or patterns behaviour of events. The following level of thinking is systemic structures which presents the causal relationship within different parts of the system

There is yet another deeper level of thinking located at the bottom of the iceberg which hardly ever comes to the surface. This is the mental model of individuals and organisations that influence why things work the way they do. Mental models reflect the beliefs, values and assumptions that we personally hold, and how they underlie our reasons for doing things the way we do $(\mathrm{K}$. Maani, E. \& Cavana, 2007). The events represent the shallowest and most visible level of reality while mental models reflect the deepest and most profound assumptions, norms and motivation. Leverage from 
events to mental models is increasing. Hence, the deeper the level we apply, the stronger is the leverage that can be perceived. The tools of systems thinking focus on the four levels of thinking, thus they provide a systemic framework to deal with the most complex or stubborn problems that we are facing in everyday life and work. Those tools include Increasing leveragecausal loop diagram, stock an flow diagram, computer simulation, learning laboratory and group modelling (K. Maani, E. \& Cavana, 2007)

Table 1. Stakeholders participation in the interview

\subsubsection{Problem structuring}

In this stage, 60 participants from 7 different groups of relevant stakeholders (Table 1) participated in focus group discussion (FGD) or key information interviews (KI) during the period of September to November 2016 to identify key issues, potential, and challenges for sustainable tourism development in lake toba.

\begin{tabular}{|l|l|l|l|l|l|l|}
\hline No & Stakeholder Groups & No. of Interviews & No. of People involve & Interview & Male & Female \\
\hline 1 & Local community & 4 & 20 & FGD & 14 & 6 \\
\hline 2 & Local Authority & 15 & 15 & FGD \& KI & 7 & 8 \\
\hline 3 & Private sector & 16 & 16 & FGD & 10 & 6 \\
\hline 4 & Academic & 2 & 2 & KI & 1 & 1 \\
\hline 5 & Non- government organization & 1 & 1 & KI & 1 & 0 \\
\hline 6 & Hotel/ Restaurant manager & 5 & 5 & KI & 1 & 4 \\
\hline 7 & Tourism Advisor & 1 & 1 & KI & 1 & \\
\hline
\end{tabular}

Table 1 Stakeholders participation in the interview . The identification of key issues is slightly different amongst groups based on their different backgrounds (see Fig. 2). The main issues identified were: (i) lack of law enforcement (ii) no waste prevention (iii) lack of coordination between stakeholders (v) Poor infrastructures and tourism facilities. These main issues are grouped into four broad categories namely politic, environmental conservation, economic development, social development as summarized in Fig. 4 as follow

\begin{tabular}{|l|l|l|l|}
\hline Politic & $\begin{array}{l}\text { Environmental } \\
\text { Conservation }\end{array}$ & $\begin{array}{l}\text { Economic } \\
\text { Development }\end{array}$ & $\begin{array}{l}\text { Social } \\
\text { Development }\end{array}$ \\
\hline $\begin{array}{l}\text { Lack of law } \\
\text { enforcement }\end{array}$ & $\begin{array}{l}\text { No waste } \\
\text { prevention }\end{array}$ & $\begin{array}{l}\text { Lack of job } \\
\text { opportunity }\end{array}$ & $\begin{array}{l}\text { Lack of } \\
\text { human } \\
\text { capacity }\end{array}$ \\
\hline $\begin{array}{l}\text { Lack of } \\
\text { coordination } \\
\text { between } \\
\text { stakeholders }\end{array}$ & $\begin{array}{l}\text { No pollution } \\
\text { control program }\end{array}$ & $\begin{array}{l}\text { Poor } \\
\text { infrastructure }\end{array}$ & $\begin{array}{l}\text { Lack of } \\
\text { hospitality }\end{array}$ \\
\hline & $\begin{array}{l}\text { Illegal forest } \\
\text { exploitation }\end{array}$ & $\begin{array}{l}\text { Poor } \\
\text { accessibility }\end{array}$ & $\begin{array}{l}\text { Poor } \\
\text { friendliness }\end{array}$ \\
\hline & & $\begin{array}{l}\text { Poor } \\
\text { amenities }\end{array}$ & \\
\hline & & $\begin{array}{l}\text { Insufficient } \\
\text { tourist } \\
\text { facilities }\end{array}$ & \\
\hline & & &
\end{tabular}

Figure 4. Key identified issues for sustainable development of tourism in Lake Toba

\subsubsection{Developing causal loop model}

UNWTO (2007) in a Practical Guide to Tourism Destination Management explained that DMOS have typically undertaken marketing activities, reviews their remit is becoming far broader, to become a strategic leader in destination development. In this study, the participants consist of local government planning committee (including tourism, agriculture and forestry, industry, natural resources, education, transportation, national park) practitioners (hotel manager, travel agent, and tourist information center), community leaders, and NGOs. About $30 \%$ of participants believes system thinking is an important approach by actors and stakeholders as an adhesive factor of cooperation (collaboration). Hardly there will be parties objected to benefit of system thinking. As a result, the concept of mutually beneficial (win-win) between related parties can be formed trough consensus. When the aspect of 'benefits' has been obtained, it is expected that each stakeholders will develop ownership which is characterized by commitment-related programs. This commitment can be seen from how much participation and empowerment can be realized. The collaborative management also can coordinate all the components to develop synergy that led to strengthening the competitiveness of Lake Toba.

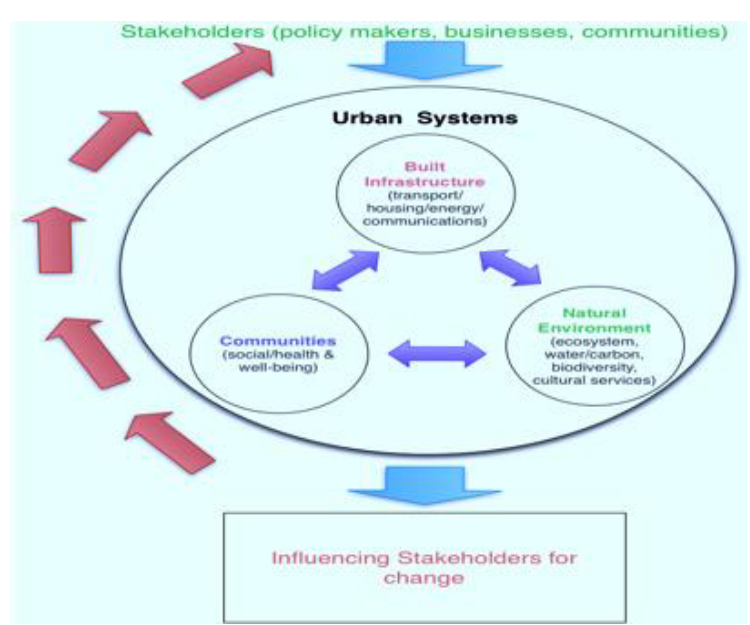

Figure 5. System Thinking (Policy makers, business and communities) with stakeholders. Modification Ricardo, 2016

Systemic thinking provides an organizing means of understanding the interconnectedness of life events in the world. Perhaps it is the lack of systemic thinking 
examples in destination management that impedes a comprehensive and wide-ranging source of applications from which one could draw. Applying systemic thinking in destination management is a difficult task largely because of systemic factors in education that compound its application. Although some resources exist that attempt to apply systemic thinking in education (see Case, 1992; Isaacson \& Bamberg, 1992), the paucity of such examples raises some possible concerns, including the misunderstanding of what is meant by systemic thinking. Some leaders need to understand more than just behavioral incidents and institutional operations. There are factors associated with each of these that may shed light on responses and solutions.

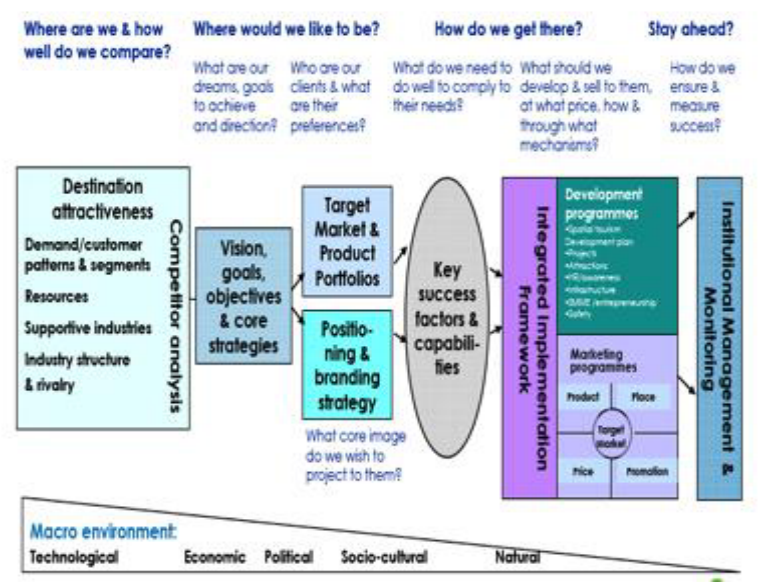

Figure 6. Integrated destination framework.

\section{Conclusion}

Destination management involves various factors includes environmental, social, health, educational, economic and political dimensions. Lake toba shows that all these aspects were brought light clearly and rational by using system thinking approach. When issuing tourism development policies, policy makers need to understand the nature of local tourism and the role of participation in policy making. In addition, they should study the results of previous tourism policies and apply policy practically (Bramwekk \& Meyer, 2007; Stevenson, Airey, \& Miller, 2008; Liu \& Wall, 2003). Policy-makers should also embrace economic, social and environmental tools to boost the development of local tourism (Panayotou, 1994; Collins, 199; Palmer \& Riera, 2003)
This study has addressed tourism as a complex and dynamic system. The system includes many interacting components. The development of tourism in a sustainable way impinges on and is subject to many different factors. This is especially true in Lake Toba context where the system includes three interacting sub-systems of economy, environment and socio-demography, and involves diverse stakeholders, each of whom holds different objectives. The process of developing a casual loop model or qualitative modeling would help governmental agencies, hoteliers and planners to understand complex relationships. This system thinking is very useful to simplify, clarify and integrate complex problems and the key leverage points of the tourism system in Lake Toba.

\section{References}

1. DeBrine, Peter. UNESCO World Heritage and Sustainable Tourism. UNESCO World Heritage Center. Paris France. UNESCO

2. Sterman D, John (2002) System Dynamic: Systems Thinking and Modeling for a Complex World. MIT Sloan School of Management Cambridge MA

3. Moejodo et al, 2006. Lake Toba: Experience and Lessons Learned Brief. Lake Toba Heritage Foundation

4. Parlagutan Siahaan. Pesan Danau Toba (Message from Lake Toba Bulletin), p. 9, September (1999)

5. Robinson, M. and Picard, D. (2006) Tourism, Culture and Sustainable Development, Division of Cultural Policies and Intercultural Dialogue, Culture Sector, UNESCO.

6. Lumbanraja,Victor (2012) Tourism Area Life Cycle in Lake Toba. IJG, 44, no. 2, December 2012 (150160) Faculty of Geography UGM and The Indonesian Geographers Association.

7. Scheyvens, Regina (2011) The challenge of sustainable development in the Maldives: Understanding the social and political dimensions of sustainability. Asia Pacific Viewpoint, 52, no. 2, , pp148-164, August (2011) 